\title{
Assessing mobility characteristics and activity levels of manual wheelchair users
}

\author{
Michelle L. Tolerico, MS; ${ }^{1-2}$ Dan Ding, PhD; ${ }^{1-2}$ Rory A. Cooper, PhD; ${ }^{1-4 *}$ Donald M. Spaeth, PhD, RET; ${ }^{1-2}$ \\ Shirley G. Fitzgerald, PhD; ${ }^{1-2}$ Rosemarie Cooper, MPT, ATP ( $^{1-2}$ Annmarie Kelleher, MS, OTR/L, ATP ${ }^{1-2}$ \\ Michael L. Boninger, $\mathrm{MD}^{1-4}$ \\ ${ }^{1}$ Department of Rehabilitation Sciences and Technology, School of Health and Rehabilitation Sciences, University of \\ Pittsburgh, Pittsburgh, PA; ${ }^{2}$ Human Engineering Research Laboratories, Department of Veterans Affairs Pittsburgh \\ Healthcare System, Pittsburgh, PA; ${ }^{3}$ Department of Physical Medicine and Rehabilitation, School of Medicine, and \\ ${ }^{4}$ Department of Bioengineering, School of Engineering, University of Pittsburgh, Pittsburgh, PA
}

\begin{abstract}
Although engaging in an active lifestyle is beneficial for maintaining quality of life, a majority of wheelchair users are inactive. This study investigated the mobility characteristics and activity levels of manual wheelchair users in the residential setting and at the National Veterans Wheelchair Games (NVWG). Demographic factors that may have influenced activity in the home environment were also identified. Fifty-two manual wheelchair users completed a brief survey, and their activity was monitored with a custom data logger over a period of 13 or 20 days. We found that they traveled a mean $+/-$ standard deviation of $2,457.0+/-1,195.7 \mathrm{~m} / \mathrm{d}$ at a speed of $0.79+/-0.19 \mathrm{~m} / \mathrm{s}$ for $8.3+/-3.3 \mathrm{~h} / \mathrm{d}$ while using their primary wheelchair in the home environment. No significant differences in mobility characteristics or activity levels were found for level of spinal cord injury or disability. We also found that subjects traveled significantly farther and faster and were active for more hours during an average day at the NVWG than in the home environment $(p<0.001)$. We found that manual wheelchair users who were employed covered more distance, accumulated more minutes, and traveled a greater average maximum distance between consecutive stops than those who were unemployed. Results from this study provide a better understanding of the activity levels achieved by manual wheelchair users and insight into factors that may influence this activity.
\end{abstract}

Key words: activity levels, activity monitor, data logger, manual wheelchair, mobility, mobility characteristics, National Veterans Wheelchair Games, physical activity, rehabilitation, wheelchair users.

\section{INTRODUCTION}

The physical and mental health benefits of an active lifestyle have been well documented for the general population [1-3]. Participating in physical activities reduces the risk of cardiovascular disease, non-insulin-dependent diabetes mellitus, osteoporosis, osteoarthritis, and several cancers [2,4-7]. Physical activity is associated with decreasing the effects of depression and anxiety and enhancing the psychological well-being of individuals $[3,8]$. The Centers for Disease Control and Prevention and the American College of Sports Medicine recommend that people participate in a minimum of 30 min of moderateintensity activity daily to achieve these health benefits [1]. Unlike previous physical activity recommendations,

Abbreviations: DDM = double-drum machine, HERL = Human Engineering Research Laboratories, NIDRR = National Institute for Disability and Rehabilitation Research, NVWG = National Veterans Wheelchair Games, SCI = spinal cord injury, $\mathrm{SD}=$ standard deviation, $\mathrm{T}=$ thoracic, $\mathrm{VA}=$ Department of Veterans Affairs.

* Address all correspondence to Rory A. Cooper, PhD; Human Engineering Research Laboratories, VA Pittsburgh Healthcare System, 7180 Highland Dr, 151R-1H, Pittsburgh, PA 15206; 412-365-4850; fax: 412-365-4858.

Email: rcooper@pitt.edu

DOI: 10.1682/JRRD.2006.02.0017 
which focused on vigorous structured leisure time activity, the current approach emphasizes incorporating activity into the daily lifestyle. While research is limited on the effects of physical activity for individuals with disabilities, many believe that individuals with disabilities can achieve similar health benefits from participating in an active lifestyle. Therefore, attaining some level of physical activity is important for individuals with disabilities because it can reduce the risk of secondary health problems that could further limit their functional independence. In addition, physical activity may also maintain or improve this group's physical capacity [9-10] and, therefore, contribute to an increased quality of life [11].

Although research clearly suggests that incorporating physical activity into one's daily lifestyle has numerous quality-of-life benefits [2,8,12], a majority of Americans live a sedentary lifestyle. Only 15 percent of Americans achieve the recommended level of physical activity [3]. Results also indicate that physical inactivity is more prevalent among individuals with disabilities than individuals without disabilities $[3,11]$. The extent to which this group of people is inactive has been difficult to quantify because of the variability that exists among individuals with disabilities and the complexity of measuring their physical activity.

Several studies focusing on the activities of individuals with spinal cord injuries (SCIs) who use a manual wheelchair have investigated the possibility of using electronic-sensor technology (e.g., accelerometers) to objectively measure intensity, duration, and frequency of activity. Use of such technology eliminates the possibility of recall bias and misinterpretation of survey questions, which are commonly associated with self-report measures [13-14]. Dearwater et al. used an electronic movement counter to compare the activity levels of 28 men with SCI over a 2-day period in a rehabilitation facility [15]. They found that individuals with paraplegia were significantly more active than those with quadriplegia in terms of the number of counts recorded on the electronic counter. Studies by Washburn and Copay [16] and Postma et al. [17] have validated the capability of various types of accelerometer-based activity monitors to measure activity and wheelchair propulsion in manual wheelchair users. While these studies found that electronic activity monitors effectively measured the activity levels of manual wheelchair users, the results were limited because the studies were conducted in controlled environments.
To get an accurate account of the activity levels achieved by manual wheelchair users, we need to conduct the tests in free-living environments. Janssen et al. used a combination of direct observation, heart rate monitoring, self-report, and an odometer to investigate physical strain during daily activity among 43 men with SCI [18]. Results indicated that physical strain (as measured by heart rate monitor) was significantly higher for subjects with quadriplegia than those with lower-level paraplegia. Although this study captured a number of the different elements that characterize physical activity, the results are limited by the length of the study and the fact that heart rate monitoring can be unreliable for assessing activity among individuals with disabilities [19].

Few studies have used data loggers to investigate activity in terms of distance and speed traveled by manual wheelchair users in different free-living environments. Fitzgerald et al. used a data logger to track the activities of community-dwelling manual wheelchair users who used a pushrim-activated power-assisted wheelchair and their own personal manual wheelchair over 4 weeks [20]. Kaminski used two different types of data loggers to investigate how far and how fast children wheelchair users typically traveled [21]. A comparison of the activity patterns based on sex revealed that male wheelchair users traveled farther and faster than female wheelchair users. The distance and speed traveled by the children were also compared with the driving characteristics of adults and were found to be similar.

Our primary objective was to investigate the mobility characteristics and activity levels of manual wheelchair users in the residential setting over the long term. Our second objective was to determine the mobility characteristics and activity levels the manual wheelchair users were capable of achieving by collecting data at the National Veterans Wheelchair Games (NVWG). The NVWG facilitates participation in a number of activities by providing ample accessible transportation to a number of venues, planned social events, and competitive wheelchair sporting events. Our intention was that the data from the NVWG measure activity that the wheelchair users were capable of achieving, while the data collected in the home realistically measure the mobility and activity levels achieved during a typical day. Our third objective was to identify demographic factors that may have influenced the mobility characteristics and activity levels of the manual wheelchair users in the home environment. 


\section{METHODS}

\section{Subject Recruitment}

Subjects were recruited to participate in this study during the 24th NVWG held in St. Louis, Missouri, in June 2004; the 25th NVWG held in Minneapolis, Minnesota, in June 2005; and the 26th NVWG held in Anchorage, Alaska, in July 2006. Subject recruitment was conducted by study personnel at the NVWG-sponsored exposition, which takes place each year during the opening day of the games. Inclusion criteria were (1) manual wheelchair as a primary source of mobility, (2) 18 years of age or older, and (3) availability to meet with study personnel to have the data logger attached to their wheelchair.

\section{Protocol}

The Department of Veterans Affairs (VA) Pittsburgh Healthcare System Institutional Review Board approved the study protocol before initiation. Participants were informed that the aim of the study was to investigate the mobility characteristics of manual wheelchair users. Signed informed consent was obtained from all subjects before the start of data collection. The participants were asked to complete a brief demographic survey. In addition, a data logger was attached to each subject's wheelchair. The data logger was placed in a location that did not obstruct the propulsion of the wheelchair or interfere with the subjects' functioning (Figure). It also required little to no attention during the study period, so individuals were able to conduct their daily activities as normal. For all subjects, the data logger monitored their wheelchair activity for 6 days during the NVWG. Participants who enrolled in the study during the 2004 NVWG were then monitored for an additional week following the games in their home environment, while participants who enrolled in the study during the 2005 and 2006 NVWG were monitored for an additional 2 weeks after returning home from the games. Therefore, subjects had the data logger attached for a total of 13 or 20 days. We implemented this protocol modification, which added an additional week of monitoring during the second and third years of testing, to ensure the data collected during the week following the NVWG represented a typical week in the home environment. After the second or third week of the study (depending on year of enrollment), subjects were instructed to remove the data logger from their

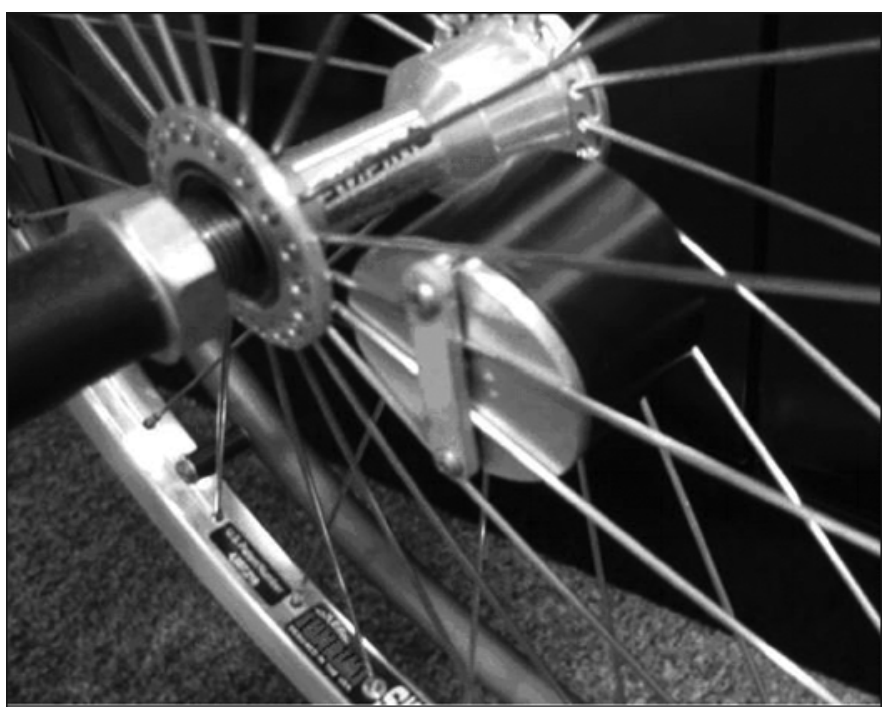

Figure.

Mounting of data logger used to monitor wheelchair activity.

wheelchair using the tools provided to them at the initial appointment and send it back to the Human Engineering Research Laboratories (HERL).

\section{Custom Data Logger}

The data logger used in this study was developed by researchers at HERL to provide a reliable method for long-term monitoring of manual wheelchair users' activities in real-world environments. The data logger is approximately $5 \mathrm{~cm}$ in diameter and $3.8 \mathrm{~cm}$ in depth. It is self-contained, lightweight, and powered by a $1 / 6 \mathrm{D}$ wafer-cell lithium battery, which enables the data logger to collect and store data for $>3$ months. The data logger easily attaches to the spokes of a manual wheelchair with a small aluminum strap and screws (Figure); therefore, no modifications to the wheelchair are required. The data logger measures the rotation of the wheelchair wheel through the use of three reed switches mounted $120^{\circ}$ apart on the back of the printed circuit board and a magnet mounted at the bottom of a pendulum. The pendulum and magnet combination, which is mounted in the aluminum base, maintains its position as a result of gravity. Therefore, whenever the wheelchair wheel exceeds $120^{\circ}$ of rotation, one of the reed switches is triggered. As each reed switch is triggered, a date and time stamp of the event to the nearest tenth of a second is recorded [22]. Three sensor hits in sequence is equal to the circumference of the wheelchair wheel. The validity of the data logger has been verified through a number of tests conducted in 
our laboratory. In one test, a manual wheelchair with two data loggers attached was repeatedly tested on a doubledrum machine (DDM) with the slats removed for 10 trials over different time intervals (between 1 and 8 h) [23]. The DDM was set at different speeds (from 0.8 to $1.8 \mathrm{~m} / \mathrm{s}$ ) for each trial. The deviations of measured distance and speed between the data loggers and the DDM were calculated as percent differences with respect to the DDM. A one-sample $t$-test with the test value at 1 percent for distance and 5 percent for speed yielded no significant differences.

\section{Surveys}

In this study, we used surveys that were developed to collect demographic data from wheelchair users. During the first year of the study, the survey included items on age, type of injury or disability, race/ethnicity, and sex. We included questions about each subject's wheelchair to understand the types of wheelchairs the study subjects used. These questions included the make and model of the primary wheelchair, age of the primary wheelchair, and number of years using a wheelchair. This survey has been successfully used in previous studies to collect demographic data on wheelchair users $[21,24]$. During the second and third years of the study, we added questions to the survey to enable a more in-depth characterization of the study sample. The additional information we collected was subjects' primary residential setting, body weight, employment status, type and frequency of use of backup wheelchair, satisfaction with primary wheelchair, ability to use transportation independently, and feelings on how the accessibility of their community influenced their daily activities.

\section{Data Reduction}

Raw data stored on the flash memory chip of the data logger were transferred to a personal computer. The raw data files were then decompressed and analyzed with a custom-designed MATLAB (The MathWorks Inc, Natick, Massachusetts) program. The custom code computed the mobility characteristic variables of daily distance $\left(D_{\text {day }}\right)$, average daily speed, and active hours. Daily distance was calculated by

$$
D_{\text {day }}=\frac{\left(\# \text { of time stamps } \times C_{\text {wheel }}\right)}{3} \text {, }
$$

where $C_{\text {wheel }}$ was the circumference of the wheelchair wheel on which the data logger was mounted. To find the average speed at which the wheelchair users traveled during a single day, we divided the total daily distance during the 24-hour period by the total amount of time the wheelchair user was moving in their wheelchair that day. Calculating the average speed at which manual wheelchair users travel in their community provides a measure of their ability to function in the community setting, similar to the way walking speed is a measure of community mobility for the general population and ambulatory individuals with disabilities [25]. Speed also gives an indication of activity intensity. The total length of time the wheelchair user was moving was defined as the total accumulated movement time. When calculating the average number of hours the wheelchair users were active per day, we considered an hour active if they traveled $>50 \mathrm{~m}$ within a 60 min time period.

The activity level variables of total accumulated movement time, number of starts/stops per $1,000 \mathrm{~m}$, maximum period of continued activity between consecutive stops, and maximum distance traveled between consecutive stops were also calculated with custom MATLAB code. The total accumulated movement time was calculated as the sum of the length of time between time stamps when the users were considered to be active (i.e., not in an idle state). Wheelchair users were considered to be idle or stopped if the amount of time between the current time stamp $t(i)$ and the next time stamp $t(i+1)$ exceeded $7 \mathrm{~s}$. The number of starts/stops per 1,000 m $\left(N_{\text {stop/1000m }}\right)$ was calculated by

$$
N_{\text {stop } / 1000 \mathrm{~m}}=\frac{N_{\text {stop } / \text { day }}}{D_{\text {day }}} \times 1,000,
$$

where $N_{\text {stop/day }}$ was the total number of stops recorded during a single day. We averaged the number of starts/ stops per $1,000 \mathrm{~m}$ to accommodate for differences in mobility levels among the subject population. To find the maximum period of continuous activity ( $\left.T_{\mathrm{max}}\right)$, we calculated the maximum length of time between two consecutive stops by

$$
T_{\max }=\max _{i}\left(T_{\text {stop }}^{i+1}-T_{\text {stop }}^{i}\right),
$$

where $T_{\text {stop }}^{i+1}$ and $T_{\text {stop }}^{i}$ represented the $(i+1)$ th and $i$ th stop, respectively, and $\max _{i}$ the largest value in this interval. Similarly, the maximum distance traveled during continuous movement was calculated by finding the maximum distance traveled each day between two consecutive stops. 


\section{Statistical Analysis}

Descriptive statistics (mean and standard deviation [SD] for continuous data and frequency for categorical data) were calculated for the demographic variables and data collected from the data loggers. To determine if the week following the NVWG represented a typical week in the home environment, we used repeated-measures analyses of variance. The mobility characteristics and activity levels of the subjects in the home environment were compared based on injury level using a Kruskal-Wallis test. We used Wilcoxon signed rank tests to determine if differences existed in the mobility characteristics and activity levels when comparing weekdays (Monday-Friday) with weekends (Saturday-Sunday) in the home environment. Comparisons were also made between the two settings (i.e., the NVWG and the home environment) to determine if differences existed in the driving behaviors of manual wheelchair users when traveling in the two different environments. When comparing data collected at the NVWG with that collected in the home environment, we used paired $t$-tests for all mobility characteristic and activity level variables, except for average maximum distance traveled. Wilcoxon signed rank tests were used for average maximum distance traveled because these data were not normally distributed. To determine whether a relationship between age and the mobility characteristics and activity level measures existed, we calculated Spearman $\left(r_{s}\right)$ correlation coefficients. We used Spearman correlations to compare years of wheelchair use and the mobility characteristics and activity levels.

We conducted additional analyses on the demographic factors that may have influenced the mobility characteristics and activity levels of subjects in their home environment. We used data from the subjects who enrolled in the study during the second and third years of testing because supplementary demographic data were collected during this time. Spearman's correlation coefficients were computed to determine if body mass was correlated to the mobility characteristics and activity levels. To determine whether the mobility characteristics and activity level variables differed with respect to employment status, we used Mann-Whitney tests. We used Kruskal-Wallis tests to investigate whether residential setting, satisfaction with primary wheelchair, and perceived influence of community accessibility on daily activities helped explain the differences in the mobility characteristics and activity levels in the home environment. All statistical analyses were completed with SPSS, version 13.0 (SPSS Inc, Chicago, Illinois) software. Statistical significance was set at $p<0.05$.

\section{RESULTS}

\section{Subjects}

Fifty-two subjects participated in this study, of which forty-seven were male and five female. The participants ranged in age from 19 to 73 years, with a mean \pm SD of $46.8 \pm 13.3$ years. The amount of time participants have used a wheelchair ranged from 1 to 45 years, with a mean \pm SD of $12.8 \pm 9.8$ years. Of the 52 subjects, 40 (77\%) used a manual wheelchair because of an SCI. Of these 40 subjects, 4 (10\%) reported having low-level tetraplegia (cervical 5-8), 9 (23\%) high-level paraplegia (thoracic [T] 1-5), 15 (37\%) midlevel paraplegia (T6-T10), and 12 (30\%) low-level paraplegia (T11-lumbar 5). The other 12 subjects reported muscular dystrophy $(n=1)$, multiple sclerosis $(n=5)$, postpolio syndrome $(n=1)$, traumatic brain injury $(n=1)$, Guillain-Barre syndrome $(n=1)$, and amputation $(n=3)$. All subjects independently propelled their manual wheelchairs. No significant differences in age or years of wheelchair use were found among the different levels of SCI and disability groups.

\section{Wheelchair Characteristics}

Fifty-one subjects (98\%) used ultralightweight wheelchairs $(<13.6 \mathrm{~kg})$ and one subject $(2 \%)$ used a lightweight chair $(<15.5 \mathrm{~kg})$ as the primary means of mobility. The age of the subjects' wheelchairs ranged from brand new ( $<1$ month old) to 22 years old, with a mean \pm SD of $3.0 \pm 3.6$ years. Table 1 provides the make and model of each of the manual wheelchairs used by the subjects.

\section{Sports Participation at NVWG}

The events available for participants to compete in at the NVWG ranged from high to low intensity. Table 2 summarizes the sporting events available for subjects to participate in and the number of subjects who participated in each event. Of the 52 subjects, 44 percent ( $n=$ 23) participated in a total of five events (the maximum number allowed), 25 percent $(n=13)$ participated in four events, 23 percent $(n=12)$ participated in three or less, and 8 percent $(n=4)$ did not participate in any events because they were volunteers. For events such as basketball, racing, and rugby, most subjects used an alternative 
JRRD, Volume 44, Number 4, 2007

Table 1.

Characteristics of subjects' wheelchairs used in study.

\begin{tabular}{|c|c|c|c|}
\hline Wheelchair Type & Manufacturer & Model & $n$ \\
\hline \multirow{21}{*}{$\begin{array}{l}\text { Ultralightweight } \\
(<13.6 \mathrm{~kg})\end{array}$} & Sunrise Medical* & XTR & 1 \\
\hline & $(n=28)$ & $2 \mathrm{HP}$ & 3 \\
\hline & & $\mathrm{Ti}$ & 10 \\
\hline & & GPV & 4 \\
\hline & & GP & 1 \\
\hline & & 2 & 6 \\
\hline & & $\mathrm{R} 2$ & 1 \\
\hline & & Revolution & 1 \\
\hline & & GT & 1 \\
\hline & Invacare $^{\dagger}(n=11)$ & TopEnd & 5 \\
\hline & & Super Pro T & 1 \\
\hline & & A4 & 3 \\
\hline & & MPV & 2 \\
\hline & TiLite $^{\ddagger}(n=9)$ & $\mathrm{X}$ & 2 \\
\hline & & ZR & 2 \\
\hline & & TR & 1 \\
\hline & & TRC & 2 \\
\hline & & SX & 2 \\
\hline & $\operatorname{Kuschall}^{\S}(n=1)$ & Airlite Pro & 1 \\
\hline & Everest and & Vision/Record & 1 \\
\hline & Jennings ${ }^{\|}(n=2)$ & Premier & 1 \\
\hline Lightweight (<15.5kg) & Invacare $^{\dagger}(n=1)$ & $9000 \times T$ & 1 \\
\hline \multicolumn{4}{|c|}{$\begin{array}{l}\text { *Sunrise Medical, Carlsbad, California. } \\
{ }^{\dagger} \text { Invacare Corp, Elyria, Ohio. } \\
{ }^{\ddagger} \text { TiLite, Kennewick, Washington. } \\
\S_{\text {}} \text { Kuschall, Longmont, Colorado. } \\
{ }^{q} \text { Everest and Jennings, St. Louis, Missouri. }\end{array}$} \\
\hline
\end{tabular}

sports wheelchair at the NVWG. Therefore, these activities were not included in the results obtained for the mobility characteristics and activity levels.

\section{Mobility Characteristics and Activity Levels}

In the home environment, we found that on some days, no activity at all was recorded. Results from the questionnaire indicated that 83 percent of the subjects owned and used a backup wheelchair and 17 percent did not. Of the subjects who owned or used a backup wheelchair, 38 percent indicated that they used their backup wheelchair at least once a week, 13 percent several times a month, and 33 percent several times a year. Based on this information, we assumed that the inactivity of the subjects who indicated using a backup wheelchair was because they used their backup wheelchair those days.
Table 2.

Number of subjects who participated in each event at National Veterans Wheelchair Games.

\begin{tabular}{lc}
\hline Event & n \\
\hline Air Gun & 19 \\
Archery & 10 \\
Basketball & 8 \\
Bowling & 27 \\
Hand Cycle & 10 \\
Nine-Ball & 13 \\
Rugby & 2 \\
Slalom & 13 \\
Softball & 12 \\
Swimming & $13^{*}$ \\
Table Tennis & 8 \\
Track (field) & $20^{*}$ \\
Track (races) & $6^{*}$ \\
Weight Lifting & 11 \\
\hline${ }^{*}$ Subjects participated in more than one event within specific category. \\
\hline \hline
\end{tabular}

The inactive days recorded for the subjects who indicated that they did not use or own a backup wheelchair were included in the analysis because we assumed that the activities represented real-world patterns of activity. Since the statistical tests indicated no significant differences between the data obtained for week 1 and week 2 in the home environment during the second and third years of testing, the data from these 2 weeks were averaged. The averaged data were used in subsequent analyses to characterize the mobility characteristics and activity levels of the subjects in the home environment.

Table 3 summarizes the subject characteristics and data collected from the data loggers for the five groups of subjects in the residential setting. Subjects with an SCI were group-based on level of injury, and subjects who reported a disability other than an SCI were considered another group. Overall, in the home environment, subjects traveled a mean \pm SD of 2,457.0 $\pm 1,195.7 \mathrm{~m}$ at a speed of $0.79 \pm 0.19 \mathrm{~m} / \mathrm{s}$ for an average of $8.3 \pm 3.3 \mathrm{~h} / \mathrm{d}$. We found that the subjects accumulated a mean \pm SD of $47.9 \pm 21.4 \mathrm{~min}$ of movement per day in the home environment using their primary wheelchair. A comparison of the mobility characteristics and activity level variables among the varying levels of SCI and disability revealed no significant differences (Table 3). When investigating if differences existed among the days of the week, we found that the mobility characteristics and activity levels were not significantly different for weekdays (MondayFriday) and weekends (Saturday-Sunday). 
Table 3.

Summary of subject demographics, mobility characteristics, and activity levels (mean \pm standard deviation) based on level of injury or disability.

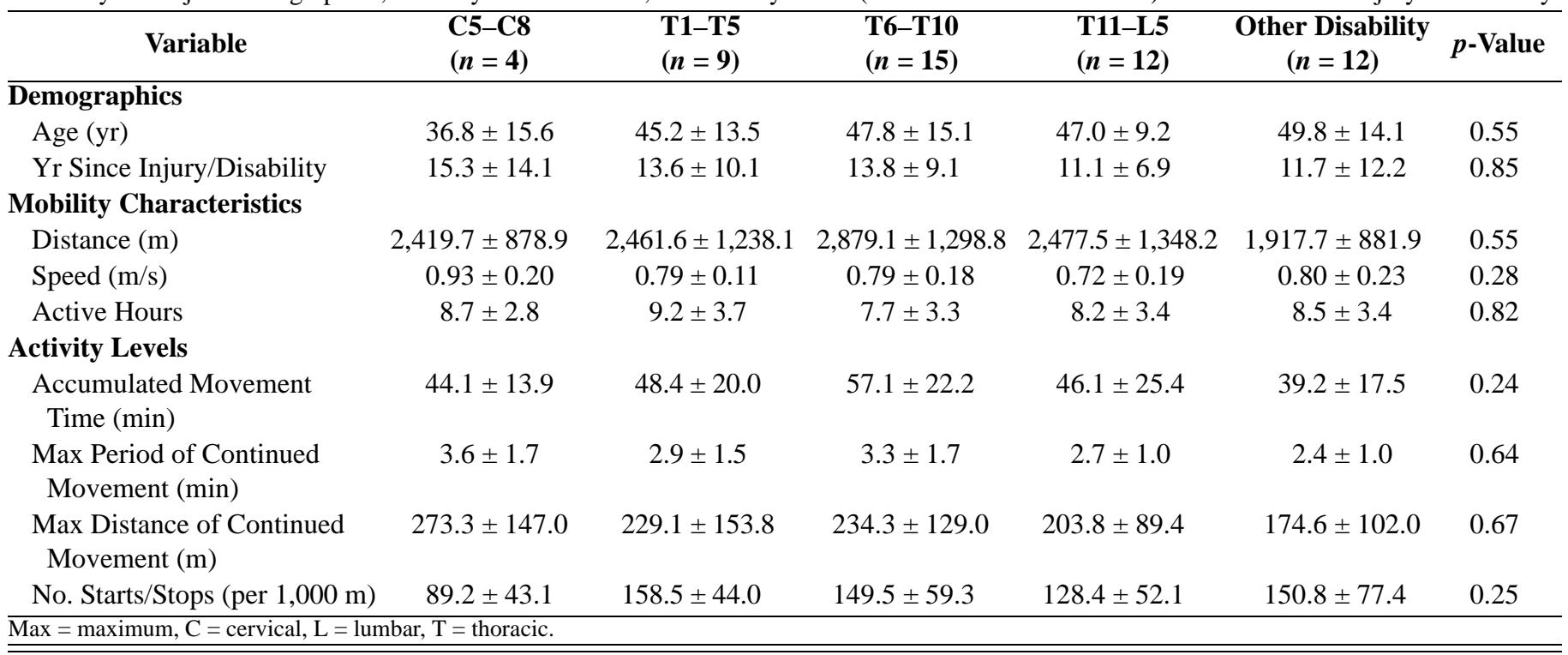

Data collected during the NVWG were used as a measure of the level of physical activity that the subjects were capable of achieving. Table 4 provides a comparison of the level of activity the manual wheelchair users achieved at the NVWG and the levels attained during daily living in the home environment when their primary wheelchair was used. The subjects traveled significantly farther, faster, and for more hours during an average day at the NVWG than in the residential setting $(p<0.001)$. While attending the NVWG, subjects traveled a mean \pm

Table 4.

Comparison of mobility characteristics and activity levels (mean \pm standard deviation) of subjects at National Veterans Wheelchair Games (NVWG) and home $(n=52)$.

\begin{tabular}{lcc}
\hline \multicolumn{1}{c}{ Variable } & NVWG & Home \\
\hline Mobility Characteristics & & \\
$\quad$ Distance (m) & $6,745.3 \pm 1,937.9$ & $2,457.0 \pm 1,195.7$ \\
$\quad$ Speed (m/s) & $0.96 \pm 0.17$ & $0.79 \pm 0.19$ \\
$\quad$ Active Hours & $12.4 \pm 1.7$ & $8.3 \pm 3.3$ \\
Activity Levels & & \\
$\quad$ Accumulated Movement & $115.9 \pm 25.5$ & $47.9 \pm 21.4$ \\
$\quad$ Time (min) & & \\
$\quad$ Max Period of Continued & $6.5 \pm 1.3$ & $2.9 \pm 1.4$ \\
$\quad$ Movement (min) & & \\
$\quad \begin{array}{l}\text { Max Distance of Continued } \\
\quad \text { Movement (m) }\end{array}$ & $519.8 \pm 177.8$ & $215.6 \pm 119.8$ \\
$\quad$ No. Starts/Stops (per 1,000 m) & $68.1 \pm 17.5$ & $141.8 \pm 60.0$ \\
\hline $\begin{array}{l}\text { Note: } p<0.001 \text { for all comparisons. } \\
\text { Max = maximum. }\end{array}$ & & \\
\hline \hline
\end{tabular}

SD of $6,745.3 \pm 1,937.9 \mathrm{~m}$ at $0.96 \pm 0.17 \mathrm{~m} / \mathrm{s}$ for $12.4 \pm$ $1.7 \mathrm{~h} / \mathrm{d}$. In addition, subjects accumulated a mean \pm SD of $115.9 \pm 25.5 \mathrm{~min}$ of movement per day over the 6-day period of the NVWG. The subjects were also found to travel significantly farther and for longer periods of time between consecutive stops $(p<0.001)$, which indicates an increased level of activity at the NVWG.

\section{Demographic Factors}

Analyses of demographic data collected for the 52 subjects revealed that age and number of years using a wheelchair were not significantly correlated with mobility characteristics and activity levels in the home environment. Table 5 summarizes the results from the additional demographic survey obtained from the subjects $(n=38)$ who enrolled in the study during the second and third years of testing. Employment status was found to be significantly related to the average daily distance traveled ( $p=0.002)$, average accumulated minutes per day $(p=0.006)$, and maximum daily distance traveled between consecutive stops ( $p=0.01$ ), with those who were employed being more active throughout the day. The self-reported body mass of the subjects ranged from 56.7 to $128.4 \mathrm{~kg}$, with a mean \pm SD of $85.4 \pm 16.0 \mathrm{~kg}$. This factor was not found to be correlated with the mobility characteristics and activity levels of the subjects. Also, no significant differences existed in the subjects' residential setting, satisfaction with primary wheelchair, and 
JRRD, Volume 44, Number 4, 2007

Table 5.

Additional demographic survey information collected during second and third years of testing.

\begin{tabular}{lc}
\hline \multicolumn{1}{c}{ Variable } & No. of Subjects (\%) \\
\hline Residential Setting $(n=38)$ & $7(18)$ \\
Rural & $8(21)$ \\
Urban & $23(61)$ \\
Suburban & \\
Satisfaction with Primary & \\
Wheelchair ( $n=38)$ & $17(45)$ \\
Very Satisfied & $14(37)$ \\
Satisfied & $4(11)$ \\
Neither Dissatisfied nor Satisfied & $2(5)$ \\
Dissatisfied & $1(3)$ \\
Very Dissatisfied & \\
Employment Status $(n=37)$ & \\
No & $24(65)$ \\
Yes & $13(35)$ \\
Perceived Influence of Community & \\
Accessibility on Activities $(n=38)$ & \\
Helps a Lot & \\
Helps Some & \\
Has No Effect & \\
Limits Some & \\
Limits a Lot & \\
Use Transportation & \\
Independently ( $n=38)$ & $5(18)$ \\
No & \\
Yes & \\
${ }^{*}$ Demographic data from one subject was missing. & $(13)$ \\
\hline \hline
\end{tabular}

perceived influence of community on activities when compared with the mobility characteristics and activity levels.

\section{DISCUSSION}

The implications of inactivity among individuals with disabilities have prompted researchers to further explore methods of quantifying the actual levels of activity achieved by this group. Using data collected from a custom data logger, we measured the mobility characteristics and activity levels of manual wheelchair users when using their primary wheelchair in the residential setting for an extended period of time. Unlike most other activity monitors and methods for measuring the activities of manual wheelchair users, the data logger was attached to the wheelchair instead of the individual. Placement of the monitoring device on the wheelchair minimized the constant reminder to subjects that their activities were being monitored. Placing the data logger on the wheelchair also reduced the potential discomfort and burden on subjects that can be experienced when the monitoring device is attached to the body. Once the data logger was attached to the wheelchair, the participant was not required to pay any attention to it throughout the entire study period. Measuring wheelchair movement instead of physiological response also eliminated the variability in response that exists because of physical and environmental factors [18-19].

Although the data logger has some advantages over other monitoring devices, it also has some inherent limitations. In this study, since the data logger was only instrumented on the subject's primary wheelchair, the results reported for some subjects were most likely underestimated. Examples of when an underestimation might have occurred include activities in which the backup or sports wheelchairs were used as well as other activities (e.g., using an arm ergometer or other exercise equipment) in which the subjects were stationary in their primary wheelchair. Another limitation of the device was that we were unable to distinguish between when the subject was independently propelling the wheelchair and when they were being pushed. However, based on the subjects recruited in this study, we believe that the distance covered when they were being pushed was minimal. Despite these limitations, the findings of this study provide important information about the typical activities of manual wheelchair users in the residential setting and activity levels these individuals are capable of achieving.

An investigation of the mobility characteristics and activity levels of manual wheelchairs users revealed that subjects traveled a mean \pm SD of 2,457.0 $\pm 1,195.7 \mathrm{~m}$ over $8.3 \pm 3.3 \mathrm{~h} / \mathrm{d}$ in their home environment. Previous research by Janssen et al. found manual wheelchair users covered a distance of approximately 4,000 m/d [18]. One reason for the discrepancy in the results may be that Janssen et al. instrumented both the primary and backup wheelchairs. Another possible explanation for the measured differences may be that a majority of the subjects in Janssen et al.'s study were either employed or students. Results from the secondary analysis of this study indicated that employment status influenced the average daily distance traveled as well as a number of other activity-level variables. An analysis of the average distance traveled by individuals who were employed in this study revealed an average daily distance covered of approximately 3,400 m, which is 
comparable with Janssen et al.'s results. Data collected on the average speed at which the wheelchair users traveled provide a measure of functional ability as well as an indication of intensity. For individuals without mobility impairments, research has shown that walking speed ranges from $74 \mathrm{~m} / \mathrm{min}$ to $89 \mathrm{~m} / \mathrm{min}(1.23 \mathrm{~m} / \mathrm{s}$ to $1.48 \mathrm{~m} / \mathrm{s})$ [26-27]. Results from this study show that the wheelchair users traveled at an average speed of $0.79 \mathrm{~m} / \mathrm{s}$, indicating that on average wheelchair users travel at a slower pace than individuals without mobility impairments.

No significant differences were found for mobility characteristics and activity levels for the different levels of SCI and disability. This finding is in contrast to other studies that have monitored the activities of individuals who use a wheelchair. In a study by Dearwater et al., individuals with paraplegia were found to be significantly more active than individuals with quadriplegia [15]. The differences in the results of our study compared with previous research might be explained simply by the fact that only four subjects with tetraplegia were included in the current study. The different measurement tools used may also explain the different results observed. Future research is needed to explore the differences in mobility and activity levels among different SCI levels. In addition, further research is needed to determine if differences exist in the mobility characteristics and activity levels of individuals who use a manual wheelchair and have a disability other than an SCI.

When comparing data obtained from the two environments, we found that the manual wheelchair users traveled significantly farther, faster, and were active for more hours per day at the NVWG than in the residential environment. These results are supported by results from previous studies, which also used a data logger to collect data on the characteristics of wheelchair users. When comparing the driving characteristics of a group of power wheelchair users who attended the NVWG with a group of power wheelchair users who resided in Pittsburgh, Pennsylvania, Cooper et al. found that the individuals who participated in the 2000 NVWG traveled farther and faster than the group of subjects monitored in their home environment [24]. The increase in activities that was found at the NVWG highlights the importance of organized activities for individuals who use a wheelchair.

Employment status was found to influence the mobility characteristics and activity levels of manual wheelchair users. The finding that individuals who are employed are more active than individuals who are unemployed is similar to results from previous research conducted by Krause [28]. In the longitudinal study by Krause, participants who were unemployed at both data collection time points were found to be less active than participants who were employed during one or both of the data collection time points [28]. Previous research has also identified a strong positive correlation between employment, adjustment after an SCI, and quality of life [29]. The increased activity levels of manual wheelchair users who were employed may be influenced by their financial ability to participate in activities or the psychological benefits gained from relationships at work that may contribute to increased self-esteem and satisfaction with life. The increased activity levels among manual wheelchair users who are employed highlight the importance of gainful employment for individuals who use a wheelchair.

Future studies will focus on collecting data on different populations of individuals who use manual wheelchairs, such as women, minorities, and individuals with a disability other than an SCI. This data could provide valuable information on whether the mobility characteristics and activity levels differ between specific populations. Collecting additional data on individuals with SCI could also offer information on the differences in the mobility characteristics and activity levels among individuals with paraplegia compared with those with tetraplegia. We will also need to attach a data logger to each subject's sports wheelchair and/or backup wheelchair as well as their primary wheelchair to acquire a more complete measure of the mobility characteristics and activity levels achieved. Determining if the subjects are involved in sports activities or other regular activities in their home environment or whether they are able to walk would also help explain the activity levels of manual wheelchair users. Future research is also needed to further explore the demographic factors that influence the mobility characteristics and activity levels of manual wheelchair users.

\section{CONCLUSIONS}

This study objectively measured the mobility characteristics and activity levels of manual wheelchair users while they used their primary wheelchairs in the residential setting. Levels of activity that the wheelchair users were capable of achieving were also captured through monitoring activity at the NVWG. We found that the 
mobility characteristics and activity levels of the wheelchair users were not significantly different when different levels of SCI and other disability were compared. In addition, the mobility characteristics and activity levels achieved by the wheelchair users were significantly different between the home environment and an environment that facilitated participation. The results also suggest that employment influences the mobility characteristics and activity levels of manual wheelchair users. The levels of activity achieved by manual wheelchair users at the NVWG highlight the benefits of organized events for wheelchair users. Future research is needed to further quantify the activities of manual wheelchair users and the factors that influence these activities.

\section{ACKNOWLEDGMENTS}

This material was based on work supported by the U.S. Department of Education, National Institute for Disability and Rehabilitation Research (NIDRR), Spinal Cord Injury Model System Center (grant H133N000019); the NIDRR Switzer Fellowship (grant H133F040006); and the VA Rehabilitation Research and Development Service (grant B3142C).

The authors have declared that no competing interests exist.

\section{REFERENCES}

1. Pate RR, Pratt M, Blair SN, Haskell WL, Macera CA, Bouchard C, Buchner D, Ettinger W, Heath GW, King AC, et al. Physical activity and public health. A recommendation from the Centers for Disease Control and Prevention and the American College of Sports Medicine. JAMA. 1995; 273(5):402-7. [PMID: 7823386]

2. U.S. Department of Health and Human Services. Physical activity and health: A report of the Surgeon General. Atlanta (GA): U.S. Department of Health and Human Services, Centers for Disease Control and Prevention, National Center for Chronic Disease Prevention and Health Promotion; 1996.

3. U.S. Department of Health and Human Services. Healthy people 2010: Understanding and improving health. 2nd ed. Washington (DC): U.S. Department of Health and Human Services; 2000.

4. Physical activity and cardiovascular health. NIH Consensus Development Panel on Physical Activity and Cardiovascular Health. JAMA. 1996;276(3):241-46. [PMID: 8667571]
5. American College of Sports Medicine. Position stand. Physical activity, physical fitness, and hypertension. Med Sci Sports Exerc. 1993;25(10):i-x. [PMID: 8231750]

6. Helmrich SP, Ragland DR, Leung RW, Paffenbarger RS. Physical activity and reduced occurrence of non-insulindependent diabetes mellitus. N Engl J Med. 1991;325(3): 147-52. [PMID: 2052059]

7. Durstine JL, Painter P, Franklin BA, Morgan D, Pitetti KH, Roberts SO. Physical activity for the chronically ill and disabled. Sports Med. 2000;30(3):207-19.

[PMID: 10999424]

8. Vuillemin A, Boini S, Bertrais S, Tessier S, Oppert JM, Hercberg S, Guillemin F, Briançon S. Leisure time physical activity and health-related quality of life. Prev Med. 2005; 41(2):562-69. [PMID: 15917053]

9. Muraki S, Tsunawake N, Tahara Y, Hiramatsu S, Yamasaki M. Multivariate analysis of factors influencing physical work capacity in wheelchair-dependent paraplegics with spinal cord injury. Eur J Appl Physiol. 2000;81(12):28-32. [PMID: 10552263]

10. Janssen TW, Van Oers CA, Rozendaal EP, Willemsen EM, Hollander AP, Van der Woude LH. Changes in physical strain and physical capacity in men with spinal cord injuries. Med Sci Sports Exerc. 1996;28(5):551-59. [PMID: 9148083]

11. Heath GW, Fentem PH. Physical activity among persons with disabilities-A public health perspective. Exerc Sport Sci Rev. 1997;25:195-234. [PMID: 9213093]

12. Rejeski WJ, Brawley LR, Shumaker SA. Physical activity and health-related quality of life. Exerc Sport Sci Rev. 1996;24:71-108. [PMID: 8744247]

13. Tudor-Locke CE, Myers AM. Challenges and opportunities for measuring physical activity in sedentary adults. Sports Med. 2001;31(2):91-100. [PMID: 11227981]

14. Tudor-Locke C. Taking steps towards increased physical activity: Using pedometers to measure and motivate. Research Digest (President's Council on Physical Fitness and Sports, Washington, DC). 2002;3(17):1-8.

15. Dearwater SR, LaPorte RE, Cauley JA, Brenes G. Assessment of physical activity in inactive populations. Med Sci Sports Exerc. 1985;17(6):651-55. [PMID: 4079736]

16. Washburn RA, Copay AG. Assessing physical activity during wheelchair pushing: Validity of a portable accelerometer. Adapt Phys Act Q. 1999;16(3):290-99.

17. Postma K, Van den Berg-Emons HJ, Bussmann JB, Sluis TA, Bergen MP, Stam HJ. Validity of the detection of wheelchair propulsion as measured with an Activity Monitor in patients with spinal cord injury. Spinal Cord. 2005; 43(9):550-57. [PMID: 15838526]

18. Janssen TW, Van Oers CA, Van der Woude LH, Hollander AP. Physical strain in daily life of wheelchair users with 
spinal cord injuries. Med Sci Sports Exerc. 1994;26(6): 661-70. [PMID: 8052104]

19. Warms C. Physical activity measurement in persons with chronic and disabling conditions: Methods, strategies, and issues. Fam Community Health. 2006;29(1 Suppl):78S-88S. [PMID: 16344640]

20. Fitzgerald SG, Arva J, Cooper RA, Dvorznak MJ, Spaeth DM, Boninger ML. A pilot study on community usage of a pushrim-activated, power-assisted wheelchair. Assist Technol. 2003;15(2):113-19. [PMID: 15137728]

21. Kaminski B. Application of a commercial data logger to electric powered and manual wheelchairs of children [thesis]. Pittsburgh (PA): University of Pittsburgh; 2004.

22. Spaeth DM, Cooper RA, Albright S, Ammer WA, Puhlman J. Development of a miniature data logger for collecting outcome measures for wheeled mobility. In: Proceedings of the 27th Annual Rehabilitation Engineering and Assistive Technology Society of North America (RESNA) Conference [CD-ROM]; 2004 Jun 20-22; Orlando, FL. Washington (DC): RESNA; 2004.

23. American National Standards Institute (ANSI)/Rehabilitation Engineering and Assistive Technology Society of North America (RESNA). American national standards for wheelchairs-Volume 1: Requirements and test methods for wheelchairs (including scooters). New York (NY): American National Standards Institute; 1998.
24. Cooper RA, Thorman T, Cooper R, Dvorznak MJ, Fitzgerald SG, Ammer W, Song-Feng G, Boninger ML. Driving characteristics of electric-powered wheelchair users: How far, fast, and often do people drive? Arch Phys Med Rehabil. 2002;83(2):250-55. [PMID: 11833031]

25. Newsam CJ, Mulroy SJ, Gronley JK, Bontrager EL, Perry J. Temporal-spatial characteristics of wheelchair propulsion. Effects of level of spinal cord injury, terrain, and propulsion rate. Am J Phys Med Rehabil. 1996;75(4):292-99. [PMID: 8777025]

26. Fisher SV, Gullickson G. Energy cost of ambulation in health and disability: A literature review. Arch Phys Med Rehabil. 1978;59(3):124-33. [PMID: 148252]

27. Blessey RL, Hislop HJ, Waters RL, Antonelli D. Metabolic energy cost of unrestrained walking. Phys Ther. 1976;56(9): 1019-24. [PMID: 959328]

28. Krause JS. Employment after spinal cord injury. Arch Phys Med Rehabil. 1992;73(2):163-69. [PMID: 1543412]

29. Krause JS, Anson CA. Adjustment after spinal cord injury: Relationship to participation in employment or educational activities. Rehabil Couns Bull. 1997;40(3):202-14.

Submitted for publication February 23, 2006. Accepted in revised form April 18, 2007. 